\title{
Group Delay Performance of Ultra Wideband Monopole Antennas for Communication Applications
}

\author{
Patrick McEvoy \\ Technological University Dublin, patrick.mcevoy@tudublin.ie \\ Matthias John \\ Technological University Dublin, matthias.john@tudublin.ie \\ Sergio Curto \\ Technological University Dublin, sergiocurtoramos@gmail.com
}

See next page for additional authors

Follow this and additional works at: https://arrow.tudublin.ie/engschececon

Part of the Electrical and Computer Engineering Commons

\section{Recommended Citation}

McEvoy, P. et al. (2008) Group delay performance of ultra wideband monopole antennas for communication applications. LAPC 2008 : Antennas and Propagation Conference, pp. 377-380. Loughborough, 17-18 March, 2008, doi:10.1109/LAPC.2008.4516945

This Conference Paper is brought to you for free and open access by the School of Electrical and Electronic Engineering at ARROW@TU Dublin. It has been accepted for inclusion in Conference papers by an authorized administrator of ARROW@TU Dublin. For more information, please contact arrow.admin@tudublin.ie, aisling.coyne@tudublin.ie,gerard.connolly@tudublin.ie.

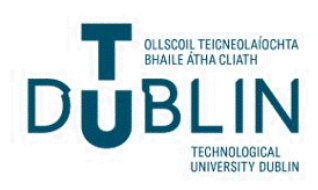


Authors

Patrick McEvoy, Matthias John, Sergio Curto, and Max Ammann

This conference paper is available at ARROW@TU Dublin: https://arrow.tudublin.ie/engschececon/20 


\title{
GROUP DELAY PERFORMANCE OF ULTRA WIDEBAND MONOPOLE ANTENNAS FOR COMMUNICATION APPLICATIONS
}

\author{
Patrick McEvoy $^{(1)}$, Matthias John ${ }^{(2)}$, Sergio Curto ${ }^{(1)}$ and Max J Ammann ${ }^{(1,2)}$ \\ (1) Antennas \& High Frequency Research Group \\ ${ }^{(2)}$ Centre for Telecommunications Value-chain Research (CTVR) \\ Dublin Institute of Technology, Kevin Street, Dublin 8, Ireland \\ Email: Patrick.McEvoy@dit.ie
}

\begin{abstract}
While limited in dimensions, the shape of small ultra wideband (UWB) antennas can significantly impact on the required gain pattern stablity and the inherent impulse spreading throughout the bandwidth. The comparative gain performance of a square monopole and two Bézier-spline shaped monopoles (optimised for low insertion losses on small groundplanes) as portable UWB device antennas solutions are reported. By measuring the transmission group delay for the three geometries in paired combinations, the time-domain spreading due to each individual antenna is solved numerically with a system of equations.
\end{abstract}

\section{Introduction}

Fig. 1 shows a square monopole alongside a set of a large and a small Bézier-spline shaped monpoles for UWB devices in the 3.1 to $10.6 \mathrm{GHz}$ band. Each of the microstrip geometies are less than $33 \mathrm{~mm}$ long and additonal dimensions can be found in [1,2]. The square monopole is a primitive shape that was selected as a simple reference geometry to study the influence of various groundplane dimensions. The rounded features of the spline antennas are a result of an Evolutionary Global Optimiser (EGO) process designed to enhance the matched bandwidth of the antennas.

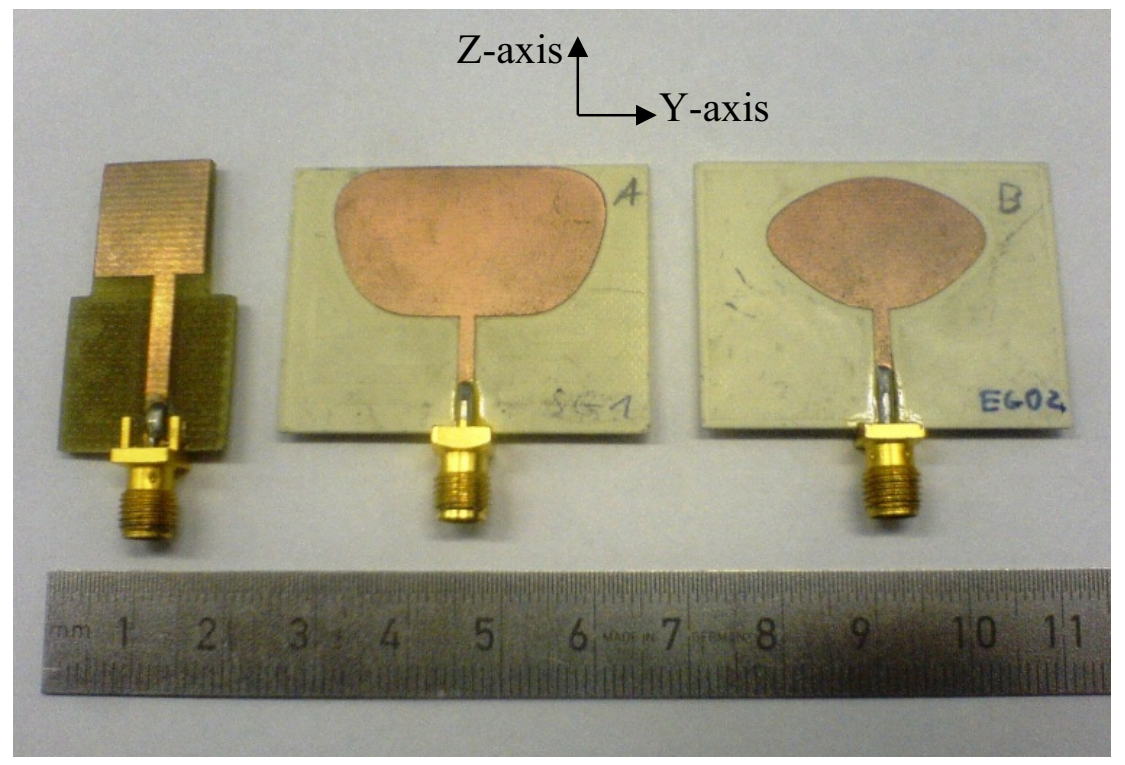

Fig. 1 Square Monopole, Large Spline and Small Spline 


\section{Measurements}

Fig. 2 to Fig. 4 show E $\theta$ polarisation plots for the $\varphi=0^{\circ}$ elevation plane and the $\theta=90^{\circ}$ azimuth plane in the UWB spectrum of the three antennas. Fig. 1 illustrates the antennas' orientation.
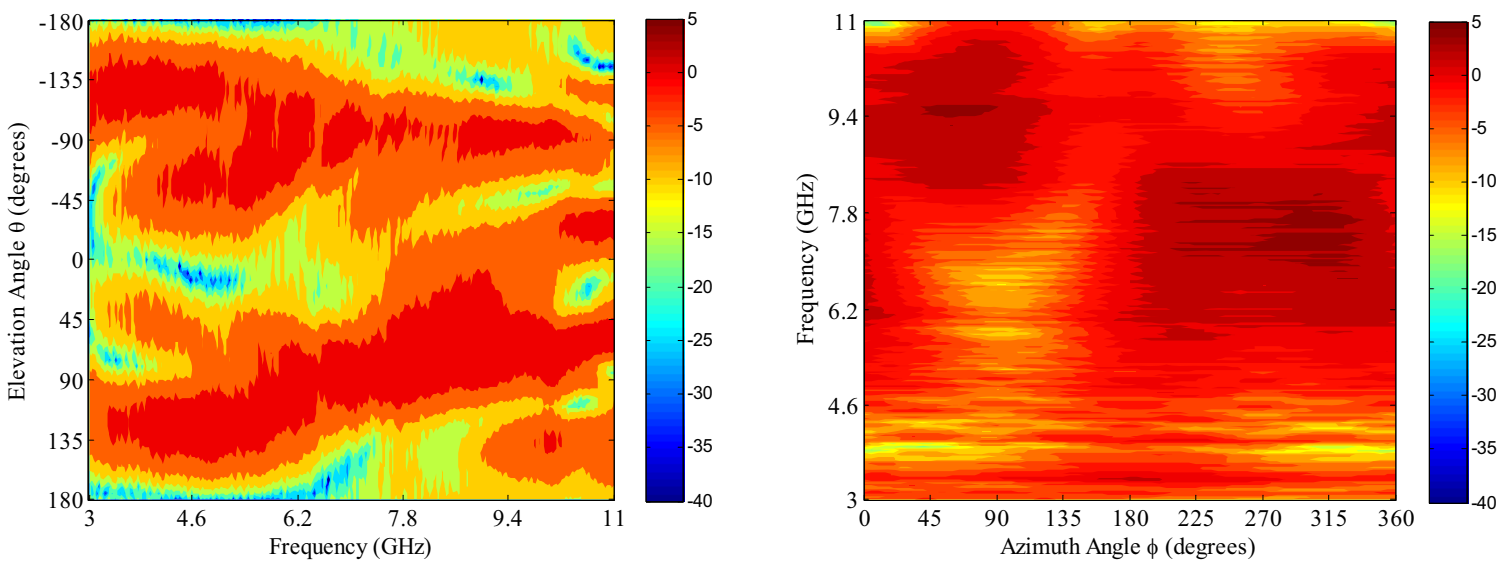

Fig. 2 Square Monopole Elevation \& Azimuth Sweep E0 Polarisation Gain (dBi)
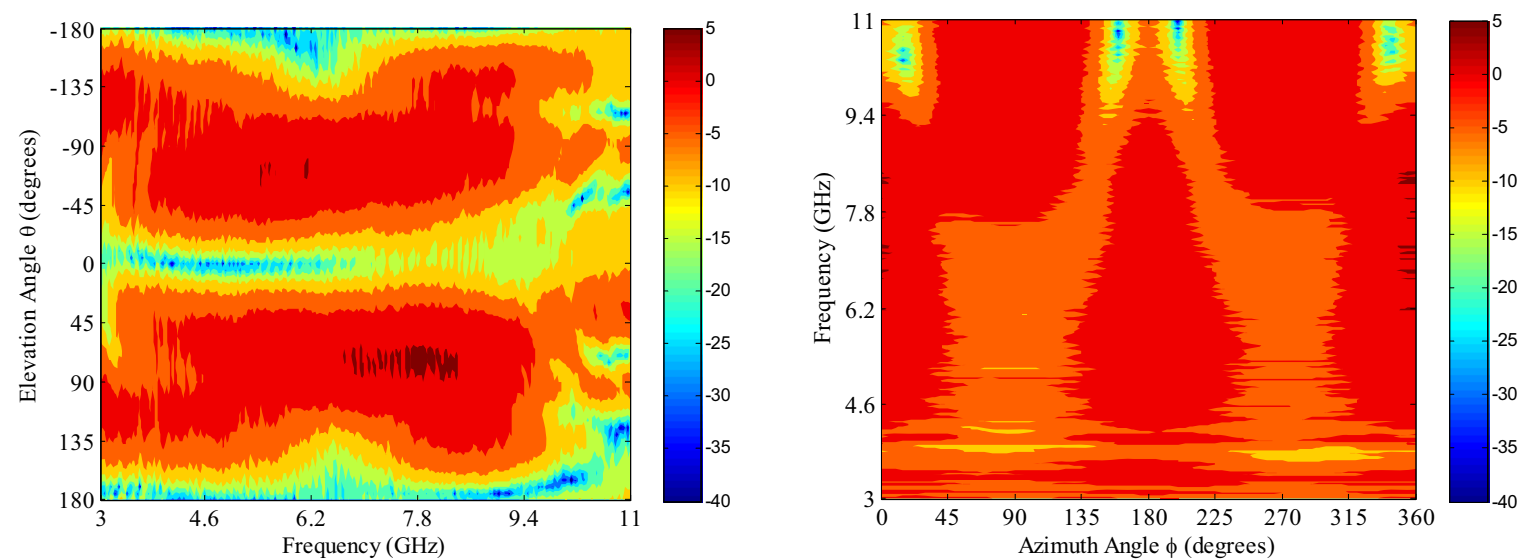

Fig. 3 Large Spline Elevation \& Azimuth Sweep E0 Polarisation Gain (dBi)
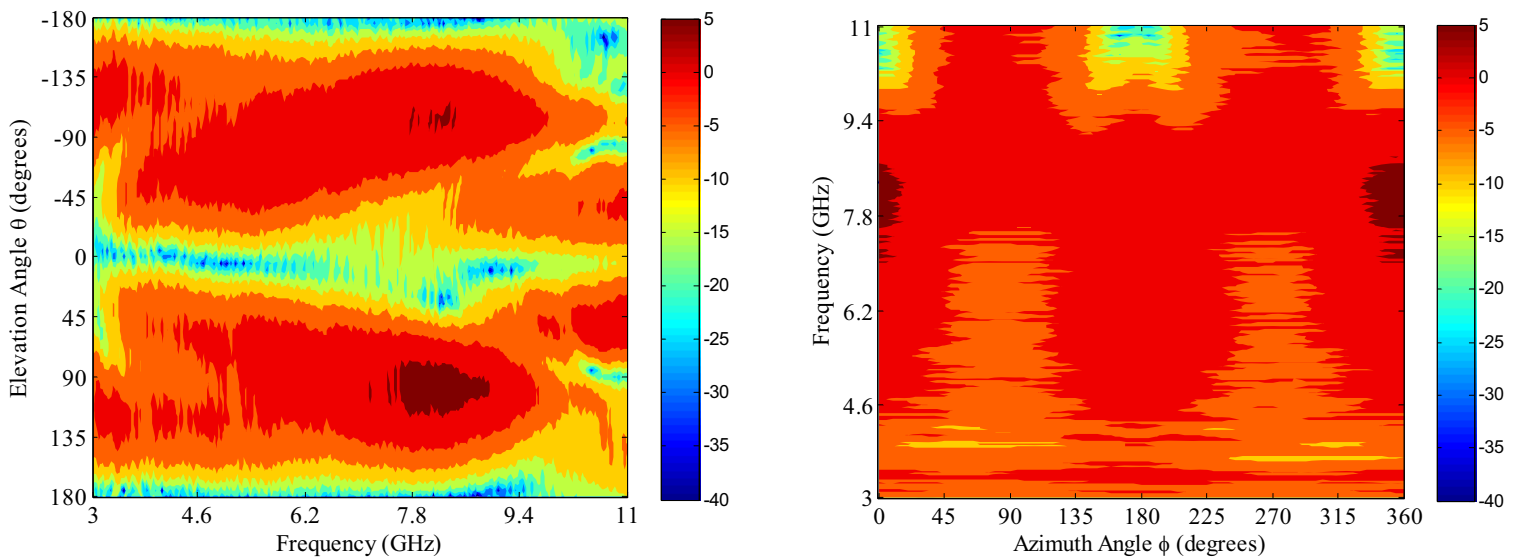

Fig. 4 Small Spline Elevation \& Azimuth Sweep E0 Polarisation Gain (dBi) 


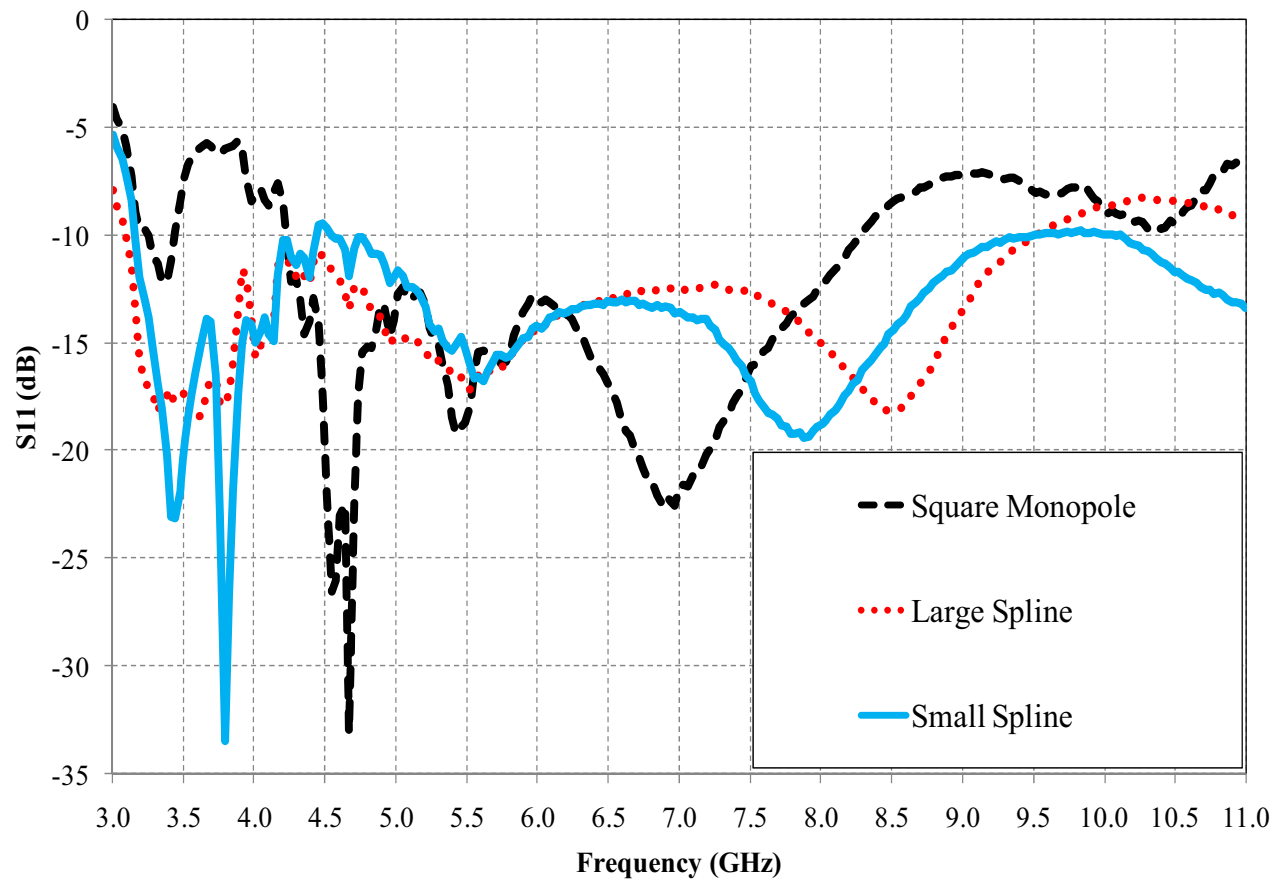

Fig. 5 S11 plot comparing the antennas

Fig. 5 shows the S11 performance of the antennas. The matched impedance bandwidth of the square monopole shows values above $-10 \mathrm{~dB}$ across a significant portion of the bandwidth. The larger spline shaped monopole shows a significant improvement, particularly in the lower end of the frequency spectrum. The smaller spline shaped geometry performs with the largest matched bandwidth. The variance in match bandwidth is attributable in part to the small groundplanes used in the measurements. If applications required higher data rates across longer ranges, extending the groundplanes will increase the stability of the communications links.

The time domain performance of UWB applications is important for pulsed based systems. In addition to radar and imaging applications, the standard has provided for their use in communications. While channel equalisation is challenging for the propagation environment, the antenna features can be optimised to reduce their inherent pulse spreading effect. The group delay is defined as the negative derivative of the phase response with respect to frequency [3]. The group delay gives an indication of the time delay that the impulse signal suffers in proportion to the various wavelength dimensions on the antenna.

Table 1 Group Delay Measurement Setup

\begin{tabular}{|c|c|c|}
\hline Measurement & Port 1 & Port 2 \\
\hline $\mathrm{AB}_{\text {Group Delay }}$ & Square Monopole & Large Spline \\
\hline $\mathrm{BC}_{\text {Group Delay }}$ & Large Spline & Small Spline \\
\hline $\mathrm{CA}_{\text {Group Delay }}$ & Small Spine & Square Monopole \\
\hline
\end{tabular}

The network analyser was set to measure the S21 group delay and the antennas were connected to the reference ports as described in Table 1 above. The antennas were separated by a 1 metre distance in an anechoic environment and were aligned in the azimuth planes at $\varphi=0^{\circ}$ respectively. Completing each measurement in a constant direction equalised the effect of the channel. 


$$
\begin{aligned}
& \text { Square Monopole }_{\text {Group Delay }}=\frac{1}{2}\left(\mathrm{AB}_{\mathrm{GD}}-\mathrm{BC}_{\mathrm{GD}}+\mathrm{CA}_{\mathrm{GD}}\right) \\
& \text { Large Spline }_{\text {Group Delay }}=\frac{1}{2}\left(\mathrm{AB}_{\mathrm{GD}}+\mathrm{BC}_{\mathrm{GD}}-\mathrm{CA}_{\mathrm{GD}}\right) \\
& \text { Small Spline }_{\text {Group Delay }}=\frac{1}{2}\left(-\mathrm{AB}_{\mathrm{GD}}+\mathrm{BC}_{\mathrm{GD}}+\mathrm{CA}_{\mathrm{GD}}\right)
\end{aligned}
$$

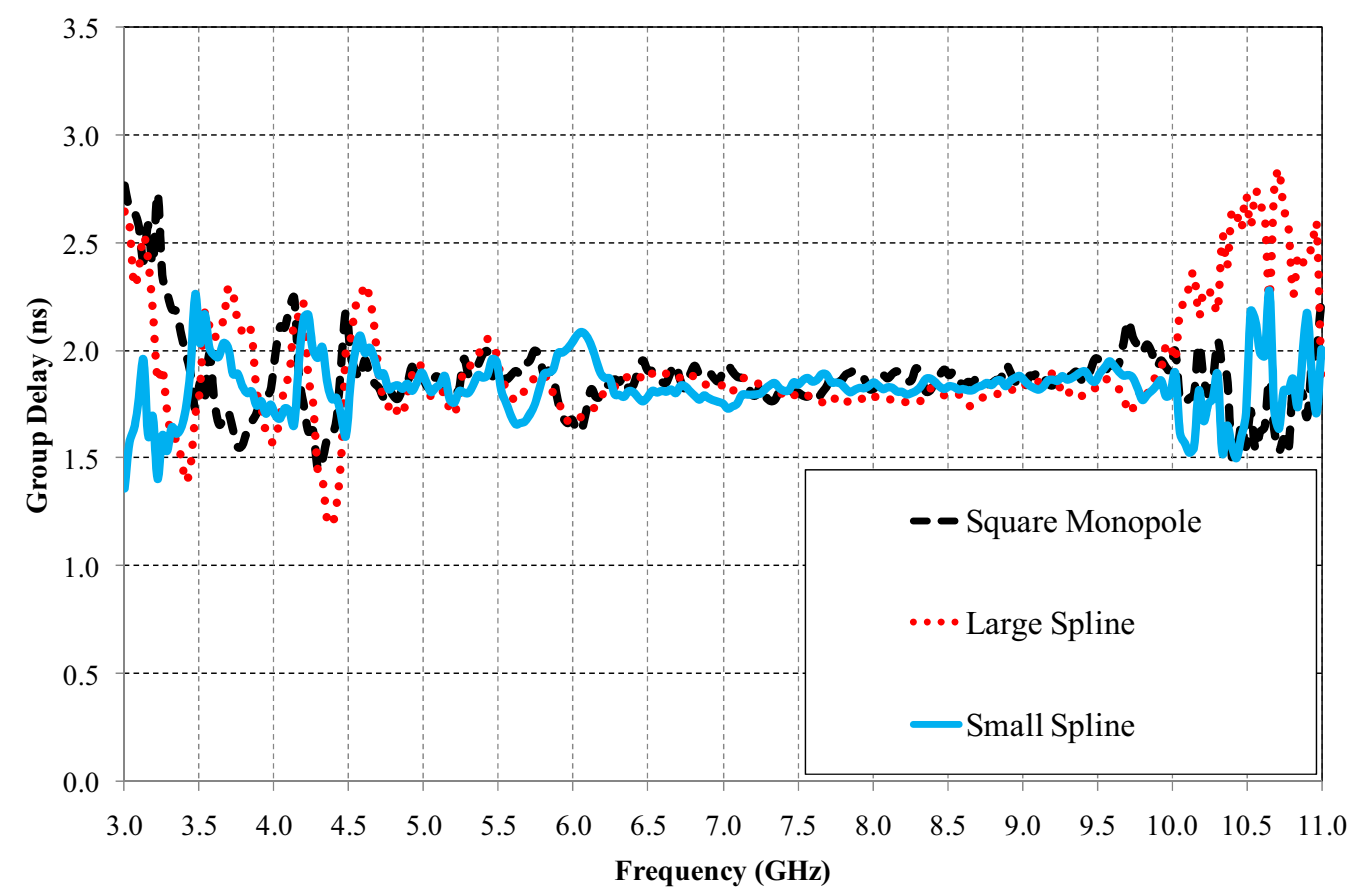

Fig. 6 Group delay comparing the antennas

\section{Conclusions}

The measured performances of three small UWB antennas for terminal applications are presented. The simple square monopole geometry has less bandwidth than the Bézier-spline shaped monopoles. The gain pattern plots illustrate reasonable pattern symmetry for the spline antennas in the lower frequencies. Measuring the transmission group delay for the three geometries in paired combinations allowed the individual antennas to be solved numerically with a system of equations, in a similar method to establishing gain using the three antenna method. The comparison of the antennas time domain performances showed that the small spline shape has less amplitude range across the bandwidth.

\section{References}

[1] S. Curto, M. John and M.J. Ammann, "Groundplane Dependent Performance of Printed Antenna for MB-OFDM-UWB," IEEE 65th Vehicular Technology Conference VTC2007-Spring, Dublin, Ireland, Institute of Electronic \& Electrical Engineers, pp. 352-356, 22/04/2007.

[2] M. John and M.J. Ammann, "Spline Based Geometry for Printed UWB Antenna Design," IEEE AP-S International Symposium on Antennas and Propagation, Vol. 1, No. 1, pp. 761764, Honolulu, Hawai'i, USA, 10/06/2007.

[3] B. Allen (Editor) et al, "Ultra Wideband Antennas and Propagation for Communications, Radar and Imaging," John Wiley \& Sons Inc, ISBN 978-0-470-03255-8, pp. 160 and pp. 204 